\title{
Thermal desorption spectrometry of beryllium plasma facing tiles exposed in the JET tokamak
}

\section{Baron-Wiechec, A.}

2018-08

Baron-Wiechec , A, Heinola , K, Likonen , J , Alves , E , Catarino , N , Coad , J P , Corregidor , V , Jepu , I , Matthews , G F , Widdowson , A \& JET Contributors 2018 , ' Thermal desorption spectrometry of beryllium plasma facing tiles exposed in the JET tokamak ', Fusion Engineering and Design , vol. 133 , pp. 135-141 . https://doi.org/10.1016/j.fusengdes.2018.05.075

http://hdl.handle.net/10138/326356

https://doi.org/10.1016/j.fusengdes.2018.05.075

cc_by_nc_nd

acceptedVersion

Downloaded from Helda, University of Helsinki institutional repository.

This is an electronic reprint of the original article.

This reprint may differ from the original in pagination and typographic detail.

Please cite the original version. 


\title{
Thermal Desorption Spectrometry of beryllium plasma facing tiles exposed in the JET tokamak.
}

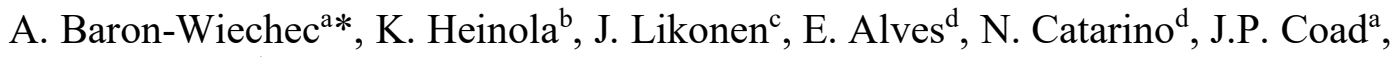 \\ V. Corregidor ${ }^{\mathrm{d}}$, I.Jepu ${ }^{\mathrm{a}, \mathrm{e}}$, G. F. Matthews ${ }^{\mathrm{a}}$, A. Widdowson ${ }^{\mathrm{a}}$ and JET Contributors* \\ ${ }^{a}$ UK Atomic Energy Authority, Culham Centre for Fusion Energy, Abingdon, OX14 3DB, UK, \\ ${ }^{b}$ University of Helsinki, P.O. Box 64, 00560 Helsinki, Finland \\ ${ }^{c}$ VTT Technical Research Centre of Finland, PO Box 1000, FIN-02044 VTT, Finland, \\ ${ }^{d} I P F N$ Instituto Superior Técnico, Universidade de Lisboa, 1049-001 Lisboa, Portugal \\ ${ }^{e}$ National Institute for Laser, Plasma and Radiation Physics Bucharest-Magurele 077125, Romania \\ * See the author list of "Overview of the JET results in support to ITER" \\ by X. Litaudon et al., 2017 Nuclear Fusion 57102001
}

\begin{abstract}
The phenomena of retention and de-trapping of deuterium (D) and tritium (T) in plasma facing components (PFC) and supporting structures must be understood in order to limit or control total $\mathrm{T}$ inventory in larger future fusion devices such as ITER, DEMO and commercial machines. The goal of this paper is to present details of the thermal desorption spectrometry (TDS) system applied in total fuel retention assessment of PFC at the Joint European Torus (JET). Examples of TDS results from beryllium (Be) wall tile samples exposed to JET plasma in PFC configuration mirroring the planned ITER PFC is shown for the first time. The method for quantifying D by comparison of results from a sample of known D content was confirmed acceptable. The D inventory calculations obtained from Ion Beam Analysis (IBA) and TDS agree well within an error associated with the extrapolation from very few data points to a large surface area.
\end{abstract}

Keywords: Thermal Desorption Spectrometry, Beryllium, Plasma Facing Component, Fuel retention, JET, Tritium

\section{Introduction}

Quantification of hydrogen $(\mathrm{H})$ and its isotopes deuterium (D) and tritium (T) in plasma facing components (PFC) of nuclear fusion devices, and assessment of trap site interactions with $\mathrm{H}$ atoms, are important from both the fundamental and technological point of view. Together with PFC erosion and deposition, plasma-surface interactions lead to $\mathrm{T}$ retention and may lead to $\mathrm{T}$ diffusion through fusion reactor structures. The phenomena of retention and de-trapping of $\mathrm{D}$ and $\mathrm{T}$ in PFC and supporting structures must be understood in order to limit or control total $\mathrm{T}$ inventory in larger future fusion devices such as ITER, DEMO and commercial machines. Current studies of $\mathrm{H}$ isotopes retention (also referred to as "fuel retention") in PFC at the Joint European Torus (JET) have two main driving forces: (i) understanding the distribution and amount of retained fuel in PFC, which will become active waste at the end of JET operations after the upcoming DTE-2 campaign, and (ii) assisting ITER [1] in predicting fuel inventory and fuel removal possibilities to satisfy safety requirements. Until 2009 JET was the world's largest magnetic fusion reactor operating with carbon PFC. These PFC were replaced with solid Be tiles and Be-coated Inconel tiles in the main chamber, and $\mathrm{W}$-coated $\mathrm{CFC}$ tiles (plus one row of solid $\mathrm{W}$ tiles) in the divertor during 2010-2011. This configuration mirrors the planned ITER PFC and is called the JET ITER-like Wall (JET ILW) [2]. Since 2010 three plasma campaigns were run with this wall configuration: ILW-1 (2011-2012), ILW-2 (2013-2014), and ILW-3 (2015-2016) which is not discussed in this paper. The
ILW-1 and ILW-2 plasma times were similar. The main difference between them however was that ILW-2 ended with an $\mathrm{H}$-fuelled campaign, in which $10 \%$ of the total number of ILW-2 pulses were performed, whereas ILW1 was predominantly a D-fuelled plasma campaign [3]. The hydrogen campaign was part of a multi-campaign programme, leading up to experiments in D-T mixtures planned for 2019. Its aims were to explore the dependence of heat, particle impurity and momentum transport in $\mathrm{H}$, $\mathrm{D}$ and H-D mixtures, and one of the objectives for the materials studies were isotope dependencies on retention and recycling of hydrogenic species [4]. Post mortem analysis of PFC components aims i.a. at providing a picture of long term fuel retention. The possible $\mathrm{T}$ inventory is estimated from the $\mathrm{D}$ retention measured on tiles exposed in JET during plasma campaigns. Deuterium retention has been studied over many years at JET by post-mortem analysis of PFC using Ion Beam Analysis (IBA) $[5,6,7,17]$, Secondary Ion Mass Spectrometry (SIMS) [8], IP imaging [9] and by gas balance [10] complemented by optical and scanning electron microscopy $[1,11]$. All these methods have limitations in estimating the total long-term fuel retention. A comparison of depth accessibility of the above-mentioned techniques and the latest addition to the analytical techniques arsenal, namely thermal desorption spectrometry (TDS), which is the subject of this paper, is shown in Table 1. The techniques are complementary to each other and give the opportunity to cross-check the results allowing a fuller picture of hydrogen isotopes retention based on all data. 
Table 1. A comparison of post mortem techniques used in study of JET plasma facing components.

Technique Species detected Area of analysis Analysis depth

\begin{tabular}{lllllllll}
\hline & $\mathrm{D}$ & $\mathrm{T}$ & $\mathrm{H}$ & tile & core & up to $1 \mu \mathrm{m}$ & up to $10 \mu \mathrm{m}$ & bulk \\
\hline IBA & $\mathrm{x}$ & & $\mathrm{x}$ & $\mathrm{x}$ & $\mathrm{x}$ & $\mathrm{x}$ & $\mathrm{x}$ & \\
\hline SIMS & $\mathrm{x}$ & $\mathrm{x}$ & $\mathrm{x}$ & & $\mathrm{x}$ & $\mathrm{x}$ & $\mathrm{x}$ & $\mathrm{x}$ \\
\hline TDS & $\mathrm{x}$ & $\mathrm{x}$ & $\mathrm{x}$ & & $\mathrm{x}$ & & & \\
\hline IP & & $\mathrm{x}$ & & $\mathrm{x}$ & $\mathrm{x}$ & $\mathrm{x}$ & & \\
\hline
\end{tabular}

Analysis of the JET components is carried out on whole tiles providing the tile fits in to the analytical chamber, or by cutting a tile into smaller samples. The samples from the tiles are prepared at VTT Helsinki in Finland (divertor tiles) and at the National Institute for Laser, Plasma and Radiation Physics in Romania (main chamber beryllium tiles) under the EUROFusion JET2 Work Programme [12]. The goal of this paper is to present details of the TDS system applied in total fuel retention assessment of PFC at JET and illustrate it with examples from beryllium (Be) wall tile samples exposed to JET plasma during ILW-1 and ILW-2.

\section{TDS system at CCFE}

This section describes the TDS system, its main features compared to standard systems. The system is an alternative to a tube furnace TDS, it operates at ultra-high vacuum (UHV) and the quadrupole mass spectrometer (QMS) is located very close to the sample in line of sight.

\subsection{System instrumentation}

The TDS system shown in Figure 1 is located in the Materials Research Facility (MRF), a part of the UK's National Nuclear User Facility (NNUF) initiative to facilitate work on radioactive and Be-contaminated samples for universities and industry within fusion and fission frameworks. The MRF provides test facilities for work on active materials that cannot be accommodated at universities because their activity levels are too high, but are not sufficiently active to require a full nuclear licenced site for analysis. The maximum activity of a research room is currently limited to $3.75 \mathrm{GBq}\left({ }^{60} \mathrm{Co}\right)$. The TDS system is located within a controlled area accessible only for Be/radiation workers to load/unload the sample loadlock chamber: all other operations are controlled from outside in a clean area. The TDS system is manufactured by Hiden Analytical Ltd (TPD Workstation type 640100). It comprises of two compartments: a stainless steel main vacuum chamber (analytical chamber), indicated by 1 in Figure la and a load/lock chamber (indicated by 2), where samples are exchanged, all mounted on a single support frame. Figures $1 \mathrm{~b}$ and $1 \mathrm{c}$ show the interior of the analysis chamber and the load/lock chamber respectively. The chambers are separated by a UHV gate valve (indicated by 3 in Figure 1a). The analytical chamber is fitted with a sample heater (indicated by 4) and a quadrupole mass spectrometer - QMS (indicated by 5) in Figure 1b. The main chamber is pumped by a turbo-pump backed by an Edwards XDS dry pump and is capable of routine UHV $\left(\sim 1.0 \times 10^{-9}\right.$ mbar) operation following occasional baking to $150^{\circ} \mathrm{C}$. The load/lock chamber is pumped by a separate turbo pump backed by an Edwards XDS dry pump, which enables it to reach a pressure of $4 \times 10^{-8}$ mbar. The load/lock chamber is flushed with Nitrogen during samples exchange. A sample transfer system (indicated by 6 in the Figure 1b) with a sample holder (indicated by 8 in Figure 1c) is used to place samples onto the sample heater which is situated directly under the entrance to the QMS. Only the sample is inserted/removed from the UHV analytical chamber to the load/lock chamber, i.e. the heated stage remains at UHV at all times.

The sample sits on a heated sample stage made of molybdenum (Mo) which is $20 \mathrm{~mm}$ diameter (4 in Figure 1b); the heating stage contains an integral water cooled shroud built into the stage to facilitate controlled cooling down rates, when required. There is no heating of the walls of the surrounding vacuum chamber; walls and other elements stay at room temperature. The heating process is realised by resistive heating elements of which the temperature is measured by a thermocouple. A second thermocouple is embedded in the Mo stage which has direct contact with the sample. Effectively the system registers the input temperature of the heater and the sample temperature. The heater temperature is fully programmable for ramp rates and various hold patterns etc. from room temperature up to $1273 \mathrm{~K}$. The sample surface temperature and the heater temperature are also measured by an infrared pyrometer indicated by the arrow in Figure 1a (RAYTEK model RAYMM2MLSF1L). It should be highlighted that the sample heating is from the "back-side" of the sample, meaning that, the plasma exposed surface is not in direct contact with the heating stage but rather facing the QMS. This is a great advantage when considering a study of fuel removal limits by an active heating/cooling system operating behind the PFC, as foreseen for ITER. The programmable hold pattern has been employed, for example, to expose JET-ILW divertor samples to the ITER baking cycle where hold times with data collection up to $15 \mathrm{hrs}$ were routinely performed [13, 23]. The gases evolved during the heating of the sample are detected by a Hiden Analytical HAL/3F RC 1051-9 PIC mass spectrometer with a Burle $4871 \mathrm{H}$ channeltron electron multiplier mounted in the vacuum chamber at line-of-sight orientation for direct detection of species desorbed from the sample. The line-of-sight setup is a suitable method for observing efficiently the gaseous 
elements desorbing from the sample. Since only the heating stage is annealed, and the rest of the chamber is at RT (and potentially acting as a cold sink for desorbed species), the line-of-sight method improves the detection by collecting efficiently the gaseous elements. The background signal is decreased by the triple-filtered QMS system, and the neutrals are avoided. Moreover and importantly, the line-of-sight positioning and close proximity allows us to detect the desorption of Be, which would not be detected with a conventional TDS setup due to the high sticking coefficient on surfaces. This allows also the unique detection of more exotic molecules being formed, such as BeD, BeD2, etc.
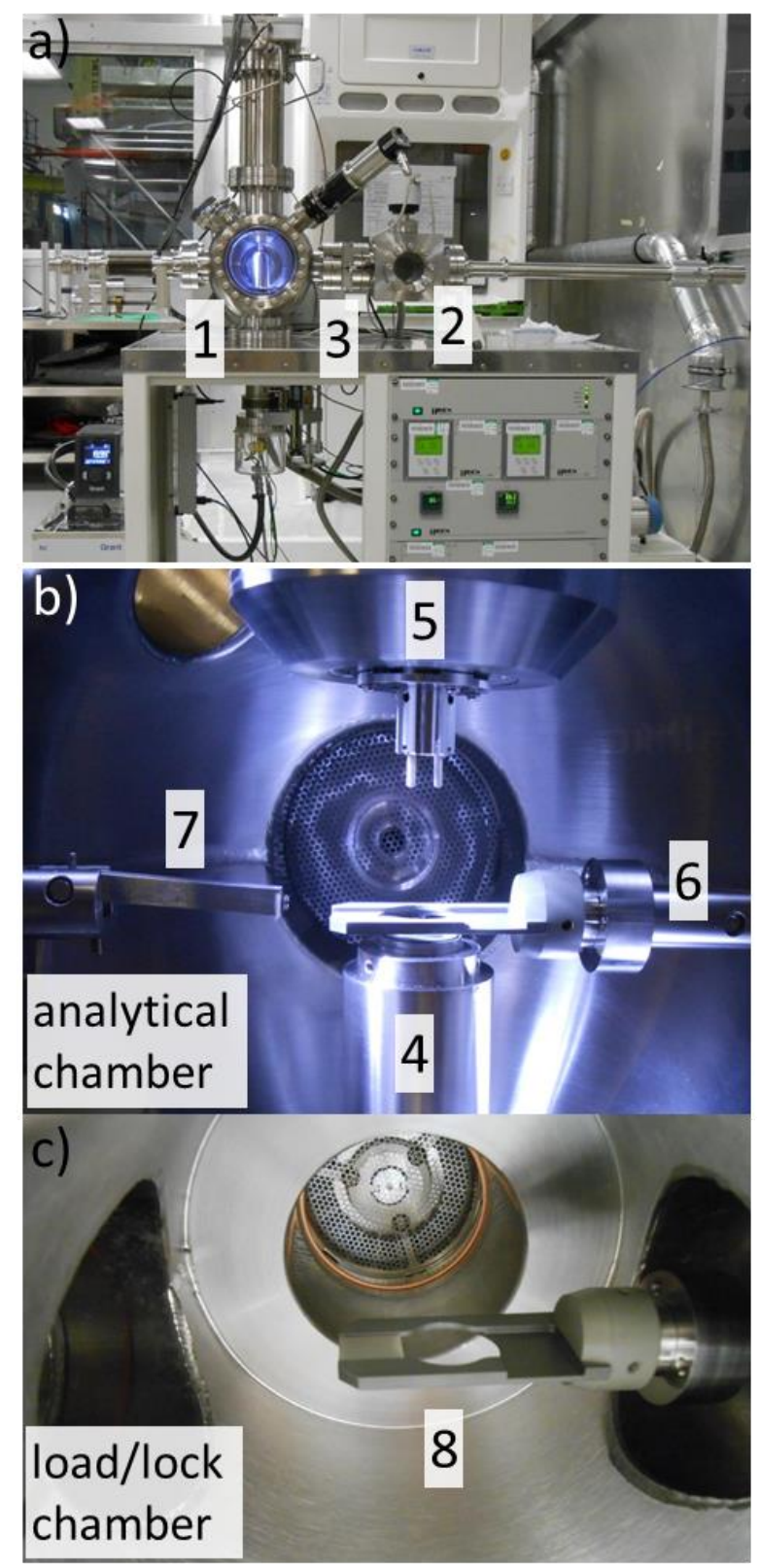

Fig. 1. An overall view of the TDS system at CCFE(a), an interior of analysis chamber(b), an interior of a load/lock chamber(c), see section 2.1 for details.

Although not demonstrated in this paper, it is worth mentioning that the system has been tuned to allow mass separation of the $\mathrm{He}$ and $\mathrm{D}_{2}$ peaks at approximately 4 atomic mass units (amu) of particular relevance for fusion samples. The mass spectrometer can be programmed for repeated mass scans (in the range 1-50 amu) or for trend mass scans as a function of time and temperature for up to 16 selected masses.

\subsection{Experimental procedure}

\subsubsection{Beryllium samples}

At each JET shutdown a poloidal selection of tiles is removed from the JET vessel for analysis to investigate material erosion and deposition, and fuel retention. From the JET-ILW main chamber made out of bulk be PFCs, examples of Inner Wall Guard Limiter (IWGL), Outer Poloidal Limiter (OPL) and Dump Plate (DP) tiles were removed. Each IWGL and OPL tile comprises a number of Be sub-tiles fastened onto an Inconel backing plate [1]. A photograph of an OPL tile discussed in this paper is shown at the top of Figure 2. The tile surface comprises a number of small segments each $\sim 12 \times 12 \mathrm{~mm}$ and referred to as "castellations". A single castellation $\leq 3 \mathrm{~mm}$ thick is a suitable sample for the TDS analysis. To achieve this size of samples a cutting program of Be tiles was developed. A detailed description of the methodology of Be cutting for analysis can be found in [12]. The samples are obtained from different in-vessel regions of the machine, and hence have been under different plasmamaterial interactions, such as erosion, deposition and implantation. A series of castellation samples were cut for TDS analysis. Details of samples from an OPL tile analyzed by TDS are shown in Figure 2. All samples from the ILW-2 campaign presented here were subjected to a step annealing procedure (sample locations indicated by white triangles and the methodology described in the next paragraph), the vast majority of samples from ILW-1 were analyzed in one step annealing (blue dots). Only two samples from corresponding locations of the tile OPL obtained for both ILW-1 and ILW-2 were analyzed using the two step annealing mode (green squares).

\subsubsection{Sample transfer between chambers}

Samples with a surface area up to $\sim 10 \times 15 \mathrm{~mm}$ are routinely accommodated, and samples $\leq 3 \mathrm{~mm}$ thick are preferable in order to minimise the temperature difference between the sample surface and the heater on which it is placed. The sample is positioned on the heater stage (4) using the transportation arm and the holder (6) described earlier in Figure 1b. Firstly a sample is placed on the holder (which also has a hole similar in size to the heater stage) in the load/lock chamber. Then the chamber is evacuated to a pressure of $5.0 \times 10^{-6}$ mbar. After reaching this value, the UHV gate valve (3, Figure 1a) is opened and the sample is moved on the holder to above the heating stage in the analytical chamber. The sample is then nudged with the transportation arm ( 7 on Figure $1 \mathrm{~b}$ ) until it is positioned through the hole in the holder onto the heater stage (4). The heater stage moves in the $\mathrm{Z}$ vertical direction for optimum sample positioning in lineof-sight with the QMS. After analysis the process is reversed by placing the hole in the holder over the sample and nudging the sample back onto the holder. For a set of 
samples from the ILW-2 campaign an additional step was introduced to the sample handling described above, referred to as "two-steps annealing" in the text. After the sample is placed on the holder in the load/lock chamber (2) and before being moved into the analytical chamber (1), the gate valve (3) is open until the vacuum in the analytical chamber reaches a steady state value, around $2.0 \times 10^{-8} \mathrm{mbar}$ and then closed again. The empty heater stage is then heated to $1270 \mathrm{~K}$, kept at this temperature for 1 hour and cooled down to base temperature of $295 \mathrm{~K}$. After this is finished the sample is transferred into the analytical chamber and the annealing procedure is carried out according to the experimental requirements. This procedure has been shown to limit the exposure of the chambers to atmosphere, both chambers stay under vacuum during the two-step annealing, and the $\mathrm{H}$ and water $\left(\mathrm{H}_{2} \mathrm{O}\right)$ background signals contributing to the sample measurement are reduced, thus enabling $\mathrm{H}$ levels in the samples to be assessed.

\subsubsection{Temperature control and measurement}

In the TDS experiment with Be samples we have to limit the maximum temperature to $1050 \mathrm{~K}$. Be has a high vapour pressure at elevated temperatures, and it is necessary to limit the amount of Be release to avoid unduly contaminating the mass spectrometer and chamber in general; in the TDS experiments it was found that the Be evaporation takes place already at $\sim 1070 \mathrm{~K}$. The JET Be samples were annealed to $1050 \mathrm{~K}$ at a ramp rate of 10 $\mathrm{K} / \mathrm{min}$ and held at the maximum temperature for 1-4 hours. The temperature was monitored in 3 ways, to enable a comparison between temperature values recorded by the thermocouple on the Mo stage, the pyrometer described in previous chapter and a calibrated web-camera (HP Webcam HD-4110) not discussed here in detail. The difference between these three independent temperature measurements of the same sample at the heating rate of $10 \mathrm{~K} / \mathrm{min}$ were $+/-25 \mathrm{~K}$, and thus show a good agreement. The main error with temperatures measured using the pyrometer and camera is due to the unknown emissivity of any deposit on the Be tile surface, which is likely to be a mixture of $\mathrm{Be}, \mathrm{W}, \mathrm{Ni}, \mathrm{C}, \mathrm{O}$ and other elements. Although the ever-present question of what emissivity to use for unknown material surfaces and how the emissivity changes at elevated temperatures remains, some good progress is being made as a part of the current TDS development making use of extensive expertise in camera calibration of the JET in-vessel protection system [14] and will be published at a later stage.

\subsubsection{Quantification of $D$ retention in PFC using a reference sample.}

There are a number of techniques for calibration TDS, such as a controlled gas leak, or samples implanted with relevant species, e.g. by using $\mathrm{TiH}_{2}$ as reference samples. Currently the TDS signals have been calibrated for D by using the reference samples, a method similar to that used by other authors, for example [16]. For this, polycrystalline $\mathrm{W}$ samples were implanted with $30 \mathrm{keV}$ $\mathrm{D}+$ to a dose of $5.8 \times 10^{16} \mathrm{D}^{+} / \mathrm{cm}^{2}$. The retained $\mathrm{D}$ concentration in the implanted $\mathrm{W}$ samples was determined with Heavy Ions Elastic Recoil Detection Analysis (HIERDA). It has been shown previously, that keV-range $\mathrm{D}$ implantation in $\mathrm{W}$ creates a number of implantation-induced defects, which act as deep trapping sites for D [15] making the samples suitable for reference use. The D concentration obtained with ERDA was used in calibrating the TDS reference and sample signals (error in ERDA measurement is likely be less than 10\%). In principle, only a single calibration is required when using this method, provided operating parameters remain unchanged, however a new calibration is required if any parameters of the TDS measurement (e.g. filament ionization energy), or TDS component (e.g. maintenance of the quadrupole system) is changed. The calibration is valid only for the system it is calibrated for. The TDS PIC voltage is checked regularly, and once its voltage is changed, a new calibration is carried out. Currently a new D implanted sample is prepared and analysed using ERDA and TDS every 10-12 months, which is more often than the requirement for PIC voltage adjustment. The TDS analyses of the D inventory of the reference sample have been shown to be in good agreement with Ion Beam Analyses carried out independently [ 1 and this paper]. We have provided samples from a similar tile location to a laboratory with a gas calibration system, and the results were within $20 \%$ of each other: A wider exercise to supply samples from the same location to four different laboratories is planned. In the future, $\mathrm{D}_{2}, \mathrm{He}$ and $\mathrm{H}$ bottles with a calibrated leak valve will be installed on the TDS system allowing routine calibrations. During annealing of Be samples, signals of $\mathrm{H}_{2}, \mathrm{HD}, \mathrm{D}_{2}, \mathrm{~T}_{2}, \mathrm{Be}, \mathrm{H}_{2} \mathrm{O}, \mathrm{HDO}$, $\mathrm{N}_{2}, \mathrm{O}_{2}, \mathrm{CO}_{2}$ were recorded. The peak areas for mass 4 deuterium (DD) and mass 3 (HD) species released were calculated and compared with the integrated peak area from a reference sample described above. The contribution of $\mathrm{D}$ from other mass numbers such as mass $19 \mathrm{HDO}$ is negligible. As with regards to quantification of $\mathrm{T}$ in the samples from D-D nuclear reaction in JET plasma the total $\mathrm{T}$ amount is based on the assumption that $\mathrm{T}$ molecules will have similar ionization properties to $D_{2}$, $\mathrm{DH}$ and $\mathrm{H}_{2}$ molecules [15], and that the detection efficiency of the T molecule is similar as the detection of D molecules.

\section{Results and discussion}

In this section the $\mathrm{D}$ inventory across a bulk beryllium main chamber OPL tile and examples of representative TDS spectra exposed during ILW-1 and ILW2 are presented. The results are obtained from the same invessel location. A detailed analysis by TDS from Wcoated CFC divertor samples can be found elsewhere [3, 13].

\subsection{D inventory across the OPL tile}

The plot in Figure 3 compares the D concentration across the midplane of an OPL tile obtained by IBA and TDS for tiles exposed to plasma during ILW-1 and ILW2. The toroidal distribution across the limiter tile shows fuel retention is low in the central region of the tile - the points of plasma contact, where erosion and temperature 
are greatest - with higher concentrations at the ends of the tile, which is generally associated with re-deposition [11]. The fuel retention patterns are similar for ILW-1 and ILW-2, however IBA results show the amount of D retained in ILW-2 is slightly less than in ILW-1. This may be the result of ILW-2 ending with a $\mathrm{H}$ campaign, which could have resulted in $\mathrm{H}$ implantation and co-deposition during this period instead of $\mathrm{D}$, or isotope exchange between $\mathrm{H}$ and the pre-existing $\mathrm{D}$ - either mechanism would result in lower D concentrations at the tile surface. Also there were more high current and power plasma pulses at this location during ILW-2 which could lead to lower D concentrations. One might expect TDS values to be higher than IBA data as IBA analysis is only to a depth of a few microns where as TDS analysis are throughout the thickness of the sample and measure release of $D_{2}$ from side surfaces of castellations. This is the case for the ILW-2 data but not the ILW-1 data where TDS and IBA data are coincident. This is first published comparison of IBA and TDS data on JET Be tiles and the reason for these differences are not fully understood and requires further investigation.

\subsection{The $D_{2}$ and $D H$ desorption from the OPL tile from ILW-2.}

Figure 4 shows D2 signal (Fig.4a) and HD signal (Fig. $4 b$ ) obtained from 5 different locations of the OPL tile, as indicated by white triangles in the Fig.2: sample 348 (left-hand side wing), sample 337 and 333 (centre), 310 and 304 (right-hand side wing). Additionally, in the Fig. $4 \mathrm{a}$, the temperatures of D2 release in the low and high temperature regions published in $[17,18]$ are indicated by solid black lines. The release temperature indicates different activation energies obtained for single crystal of Be of a very clean surface [17] and are used in the discussion as reference points. The ramp rate used in [17] is 6 times higher than for the experiment reported here and as a consequence the comparable release peaks in the current experiment appear at a lower temperature than it is shown in [17].

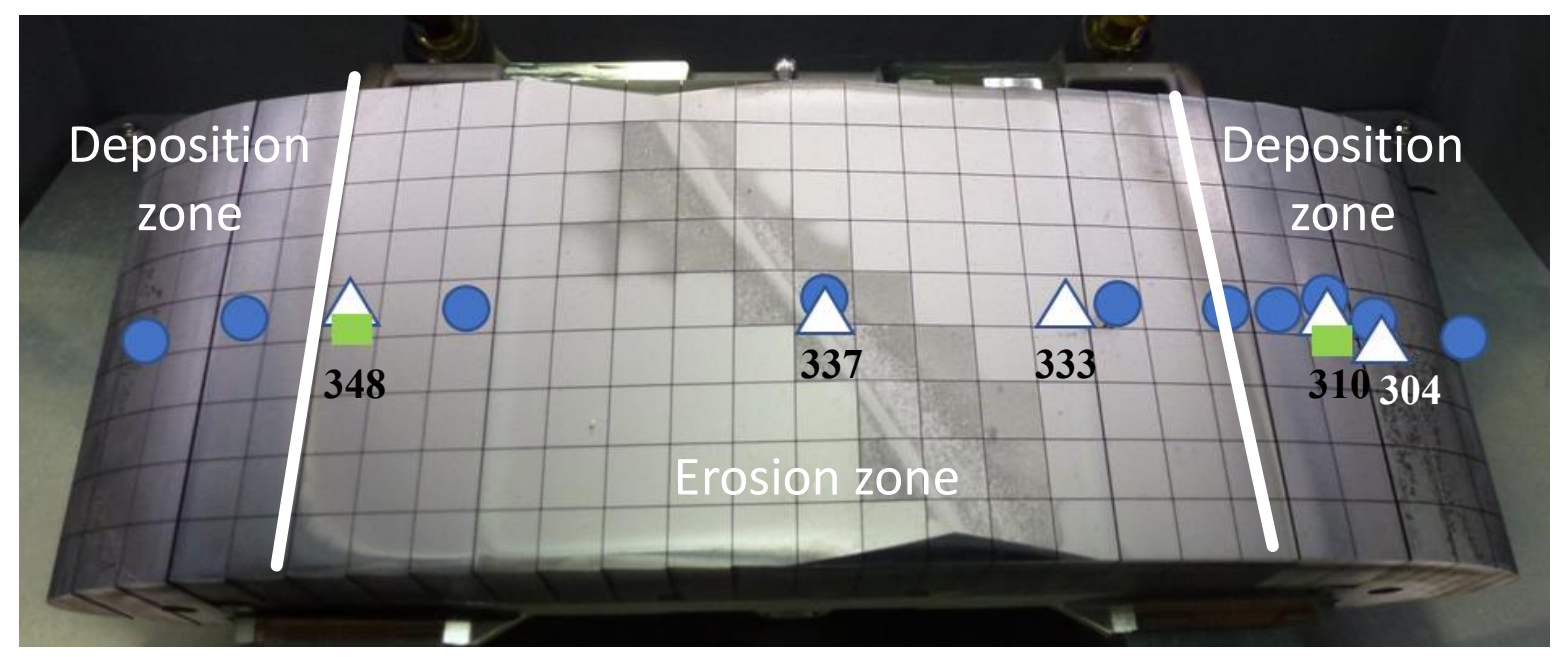

Fig. 2. A photograph of the OPL tile from ILW-2.Symbols: O-ILW1, $\boldsymbol{\Delta}$-ILW2, $\square$ - ILW1 and ILW2 two-step annealing. A detailed description of an indicated location of the analysed samples by means of TDS from ILW-1 and ILW-2 is in the paragraph 2.2.1.

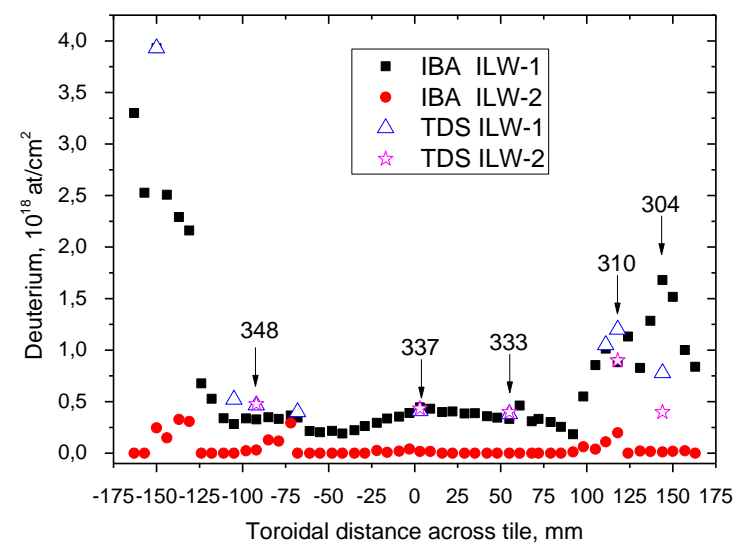

Fig.3. A Comparison of the D concentration across the OPL tile exposed during ILW-1 and ILW-2 obtained by IBA and TDS.
An additional factor adding the difference between the two studies is that the implantations energies expected for OPL mid-plane Be JET samples are below $100 \mathrm{eV}$ compared with 1-3 keV in [17]. Distinct from the Be analysis presented in $[16,17]$, the Be JET samples were exposed to varying plasma conditions during plasma campaign leading to surface erosion or deposition, and varying surface temperatures, making the interpretation of the results very difficult and sometimes ambiguous.

Nevertheless a few similarities to the results found in [17] can be noticed. Firstly, the desorption peaks at the $440 \mathrm{~K}$ and $470 \mathrm{~K}$ do not exist, only peaks above $480 \mathrm{~K}$ are present. This can be due to heat loads that prevent $\mathrm{D}_{2}$ from being retain in low energy traps resulting in recycling during operations, or due to implantation fluencies lower than the threshold $1 \times 10^{-17} \mathrm{~cm}^{2}$ as reported in $[17,18]$. Above $480 \mathrm{~K}$ most of the $\mathrm{D}$ in pure Be is retained in ion induced traps sites generated during particle 
bombardment and implantation, at grain boundaries or clusters. However, the high temperature release from JET samples might be due to surface contamination or presence of deposit and not necessarily linked to implantation in the bulk even in the erosion zone. Three $\mathrm{D}_{2}$ release peaks are present at $\sim 770-790 \mathrm{~K}, \sim 820-850 \mathrm{~K}$ and $\sim 900-920 \mathrm{~K}$ obtained for sample 337 and 333 from the erosion zone show, Fig.4a. The overall $\mathrm{D}_{2}$ retention is the lowest among the analysed locations, but the maximum of the release takes place at the highest temperature of all (indicated by green lines in Fig 4a). It is clear that detailed microscopy analysis of cross-section of the erosion zone would be useful, all the more so since the IBA shows very small deposit of tungsten and other heavier elements in the erosion zones of approximately $20-40 \times 10^{15} \mathrm{at} / \mathrm{cm}^{2}$ [11]. The highest $\mathrm{D}_{2}$ retention is observed for sample 310 from the deposition zone, and the most intense release takes place between $715 \mathrm{~K}$ and $875 \mathrm{~K}$. Also an additional component is observed at lower temperature, namely at $\sim 680 \mathrm{~K}$. The same component is observed more clearly on the spectra of sample 304, located just next to the 310 in the deposition zone. However one must remember that sample 304 is likely to be exposed to lower heat loads, lower fluxes and lower energy of the incoming particles during plasma wall interaction. This may suggest that that the release is from the traps in the deposit rather than from the high energetic traps in the bulk of the material. The sample 348 from the erosion/deposition zone has two pronounced peaks at $\sim 840 \mathrm{~K}$ and $\sim 915 \mathrm{~K}$, and also marginally elevated background starting at around $700 \mathrm{~K}$, which may indicate a third peak, similar to the one observed in samples 304 and 310.

Summarising, based on the desorption spectra it can be concluded that the majority of the $\mathrm{D}_{2}$ and $\mathrm{DH}$ release from the analysed OPL tile takes place between $670 \mathrm{~K}$ and $950 \mathrm{~K}$. The high temperature release at $840 \mathrm{~K}$ and $925 \mathrm{~K}$ is not present for the single crystal Be samples implanted at elevated temperatures reported in [17]. As indicated in
[19] the shift in the desorption peak position is affected by the annealing ramp rate. For the purpose of comparison, it may be expected that a decrease of the annealing ramp rate by factor of $6(10 \mathrm{~K} / \mathrm{min}$ in our experiment and $60 \mathrm{~K} / \mathrm{min}$ in [17]) would shift the peak position towards lower temperature. It would mean that in order to relate our results with [17], the desorption peaks for Be JET samples should be found at around $120 \mathrm{~K}$ lower temperature, which is not the case here. One may accept a two-fold approach how to interpret the discrepancy: for experimental results the shift is smaller and do not exceed 20-50 K, or one may accept that the retention mechanism in Be JET samples differs, and the high temperature traps are present between $775 \mathrm{~K}$ and $950 \mathrm{~K}$. Also, any shift of the temperature of the release peaks towards the higher temperature compare with the data published in [17] may be due to many other factors: (i) polycrystalline vs. single crystal material, (ii) surface contaminated by deposits $(\mathrm{O}$, $\mathrm{C}, \mathrm{N}, \mathrm{W}, \mathrm{Ni}$, etc ) vs. very clean surface, (iii) varying D fluence and energy of the incoming particles vs. controlled implantation parameters. Especially the unavoidable surface contamination and presence of oxygen in the bulk of JET samples may be responsible for introducing an energetic barrier to the recombination process. Not all the $\mathrm{D}$ is released as $\mathrm{D}_{2}$. There is a significant release of HD which is observed at mass 3, Fig.4b. The release spectrum has a similar shape to that for $\mathrm{D}_{2}$ as a function of temperature for the analysed samples from the OPL tile from the ILW-2. The HD signal intensity is higher compare to the $\mathrm{D}_{2}$ signal for all analysed samples excluding sample 348, for which the intensity is comparable. On the contrary, for corresponding samples exposed during ILW-1, not shown here, the HD signal has lower intensity than the $\mathrm{D}_{2}$ signal (this is also true for the divertor tiles). The large $\mathrm{H} 2$ signal following ILW-2 (discussed later) must be a true release from analysed ILW-2 tile samples inherited from the $\mathrm{H}$ plasma campaign. This must also be the reason for the increased HD contribution as such a large HD signal
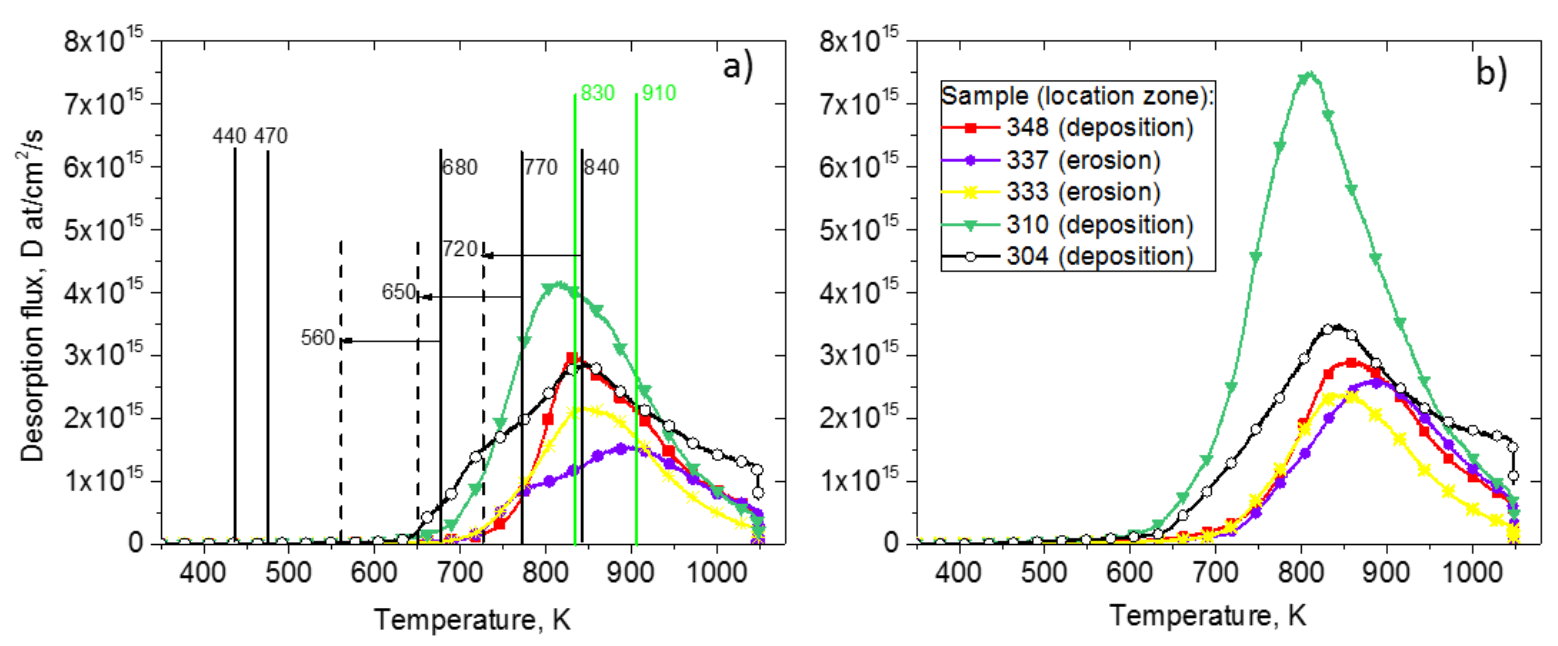

Fig. 4. (a) TDS spectra of mass 4 (D2) and (b) mass 3 (HD) release flux from the OPL tile: erosion/deposition zone (sample 348 - left hand side and 333 - right hand side), a central location (sample 337) and the deposition zone (sample 310 and 304), as indicated in Figure 2, OPL exposed to the plasma during ILW-2. 
cannot be simply explained by formation of HD molecules in the analytical chamber walls or vacuum pumps. The formation of HD molecules was observed in experiments on the interaction of $\mathrm{D}+$ ions and $\mathrm{D} 2$ gas with various materials, e.g. $\mathrm{Nb}, \mathrm{Pd}, \mathrm{W}, \mathrm{Mo}$, and graphite [25]. Various sources can contribute to the HD yield in different situations: vacuum pumps, the mass spectrometer, the surfaces surrounding and the sample itself. The quantity of deuterium desorbed as HD can be equal or higher to $\mathrm{D}_{2}$ depending on the various $\mathrm{H}$ sources. Therefore the effect of isotope mixing must be taken into account when analysing experimental data on the behaviour of hydrogen isotopes in PFC materials. A small mass 19 peak (HDO) has been observed in W-CFC divertor samples which contributes no more than $5 \%$ to the overall $\mathrm{D}$ amount but there has been no detectable D release as hydrocarbons: neither HDO nor hydrocarbon peaks have been noticed.

\subsection{Comparison of the $\mathrm{H}_{2}$ desorption of the OPL tile from ILW1 and ILW2.}

Close examination of the individual $\mathrm{H}_{2}$ (mass 2) TDS spectra obtained for the same in-vessel locations shows differences between ILW-1 and ILW-2 data. Figure 5 shows examples of TDS spectra of $\mathrm{H}_{2}$ registered from corresponding locations from samples exposed during ILW-1 and ILW-2 compared with $\mathrm{H}_{2}$ background signal obtained during annealing the empty heating stage to $1270 \mathrm{~K}$ against temperature.

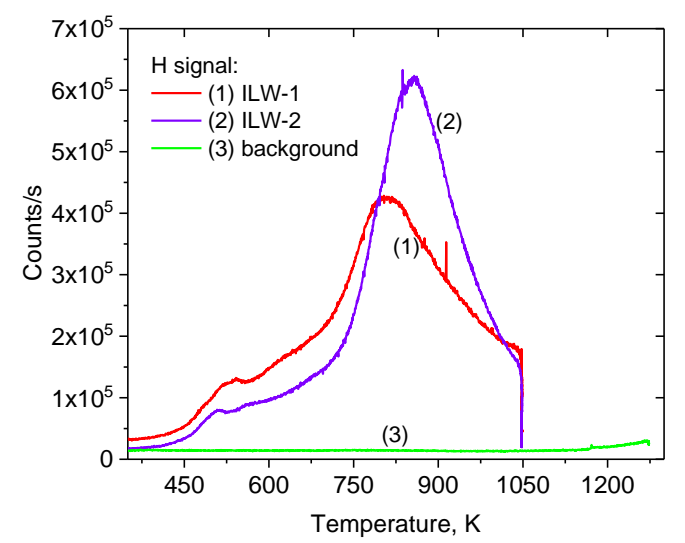

Fig. 5. TDS spectra of $\mathrm{H}_{2}$ signal obtained for sample 304 of the tile exposed during ILW-1 (1), and from the corresponding location exposed during ILW-2 (2), both annealed to $1050 \mathrm{~K}$, and $\mathrm{H}_{2}$ background signal obtained during annealing the empty heating stage to $1270 \mathrm{~K}$ (3).

The surface area of samples is the same. Integrated H2 signal from the ILW2 is higher than for ILW-2 by $13-19 \%$ for the analysed set of samples. The amount of puffed in $\mathrm{H}$ atoms during ILW-1 (D-D) was approximately 12 times higher: $\sim 3.3 \times 1025 \mathrm{H}$ atoms in ILW1 and 2.7x1024H atoms in ILW-2 (D-D and H-H). The effect of H-only plasmas is seen as decrease of the $\mathrm{D}$ fuel retention in the near-surface regions of the JET divertor plasma-facing components [3]. It is noticeable that for JET Be tiles from ILW-2 campaign the $\mathrm{H} 2$ content is higher than in ILW-1, however the overall D2 retention is comparable.

\subsection{Tritium presence in the beryllium OPL tile.}

The TDS installation in the MRF allows for tritium (T) analysis and it is extensively used for the analysis of $\mathrm{T}$ implanted from DD reactions in the JET plasma into PFC. Figure 6 includes release spectra for T2 (mass 6) and DT (mass 5) from the same samples as discussed before: erosion and deposition zones along the OPL tile (locations indicated by white triangles in Figure 2). There is a $\mathrm{T}$ release at $600-800 \mathrm{~K}$ and some release over the temperature range of the first major component seen for release from the divertor sample [13], but due to the onset of significant Be evaporation, the Be samples were not heated to sufficient temperature to observe whether there is a second release component above $1050 \mathrm{~K}$. It should be noted that there is approximately $20-80 \%$ less $\mathrm{T}_{2}$ release from the Be samples than from the divertor sample (not presented here) at the temperatures below $1050 \mathrm{~K}$, depending on the location. Since there are relatively few $\mathrm{T}$ atoms being released compared to $\mathrm{D}$ or $\mathrm{H}$, it might be expected that a $\mathrm{T}$ atom reaching the surface would have a high probability of combining with a $\mathrm{D}$ or $\mathrm{H}$ atom. $\mathrm{T}$ present in DT (mass 5) accounts for $\sim 20-30 \%$ of the total $\mathrm{T}$ and is mostly released in the range $\sim 600-850 \mathrm{~K}$. Currently, it is not possible to distinguish HT from $\mathrm{D}_{2}$, hence the contribution of HT in mass 4 remains unsolved.
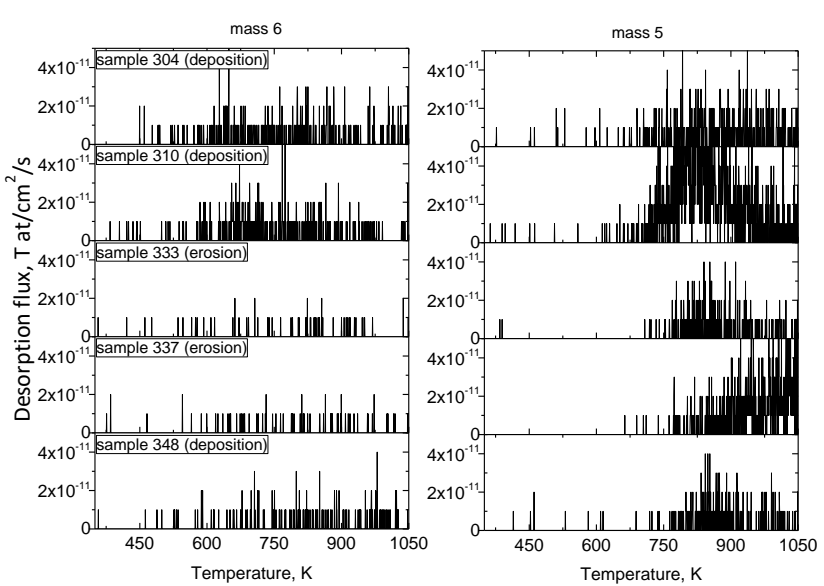

Fig. 6. Spectra for and $T_{2}$ (mass 6) and DT (mass 5) from locations indicated by white triangles in Fig. 2.

\section{Summary}

The TDS system at CCFE is being used to analyse the amount of the plasma fuelling gas: D, H and fusiongenerated $\mathrm{T}$ that is trapped in plasma-facing components during JET-ILW operations and is a crucial part of experiments to determine the total amount of fuel that is retained during operations. As samples are only available from a limited area of the JET main chamber, only an approximate global fuel inventory may be estimated, which is summarised partially in [1] and is a subject of a future publication. The global trends cannot be assessed yet for ILW-2 as the analysis is ongoing, and data from ILW-3 is yet to be collected. However, based on the available data one may assume that the retention trends for all campaigns will be similar. In this paper the first detailed results comparing TDS and IBA data on JET Be tiles from ILW-1and ILW-2 are presented. Whilst there are some unanswered questions relating to the 
comparative magnitude of IBA and TDS results, the first results show encouraging agreement between the two techniques. Consequently a valuable $\mathrm{A}$ valuable conclusion for our work using TDS system is that the method for quantifying D by comparison of results from a sample of known D content is acceptable. There are a few techniques available for analysis of hydrogen, however with careful conditioning of the TDS equipment, differences in $\mathrm{H}$ concentrations have been observed which correlate with JET operation with H. Many laboratory experiments have been dedicated to the loading, retention and desorption mechanism of $\mathrm{H}$ isotopes in co-deposits with beryllium [22 and references therein, 23, 24]. However the JET samples are more complex, because

\section{Acknowledgments}

This work has been carried out within the framework of the EUROFusion Consortium and has received funding from the Euratom research and training programme 2014-2018 under grant agreement No 633053 and from the RCUK Energy Programme [grant number EP/P012450/1]. The views and opinions expressed herein do not necessarily reflect those of the European Commission. The research used UKAEA's Materials Research Facility, which has been funded by and is part of the UK's National Nuclear User Facility and Henry Royce Institute for Advanced Materials.

\section{References}

[1] A. Widdowson et al., Overview of fuel inventory in JET with the ITER-like wall, Nuclear Fusion, 57 (2017) 8

[2] G.F. Matthews et al., JET ITER-like wall—overview and experimental programme, Physica Scripta T145 (2011) 014001

[3] K. Heinola et al. Experience on divertor fuel retention after two ITER-Like Wall campaigns, Physica Scripta T170 (2017) 014063

[4] I. Nunes et al., First results from recent JET experiments in Hydrogen and Hydrogen-Deuterium plasmas, 26th IAEA Fusion Energy Conference, Kyoto, Japan, October, 17-22, 2016

[5] N. Catarino et al., Assessment of erosion, deposition and fuel retention in the JET-ILW divertor from ion beam analysis data, Nuclear Materials and Energy (2016) in press

[6] M. Mayer et al., Erosion and deposition in the JET divertor during the first ILW campaign, Physica ScriptaT167 (2016) 014051

[7] P. Petersson et al., Co-deposited layers in the divertor region of JET-ILW, Journal of Nuclear Materials 463 (2015) 814-7

[8] S. Koivuranta et al., Post-mortem measurements of fuel retention at JET, Physica Scripta T159 (2014) 014052

[9] Y.Hatano et al., Tritium analysis of divertor tiles used in JET ITER-Like wall campaigns by Means of $\beta$-ray Induced X-ray Spectrometry", PhysicaScripta in press.

[10] T. Loarer et al. Comparison of long term fuel retention in JET between carbon and the ITER-Like Wall, Journal of Nuclear Materials, 438 (2016) S108-13

[11] A. Baron-Wiechec et al. Global erosion and deposition patterns in JET with the ITER-like wall, Journal of Nuclear they contain varying amounts of impurities (e.g. C, O, Ni and $\mathrm{W}$ on Be tiles) and morphology of the deposit or the surface due to plasma-wall interactions and material migration in the machine, which in turn may change the release characteristics. For this reason, some similarities between the results obtained in the well-controlled laboratory experiments presented in the available literature and the JET experiments results are very encouraging. It is clear that the joint effort between modelers, experimentalists, and continuation of the EUROFusion efforts in extracting and analysing of the real samples from working tokamaks, are necessary to make meaningful progress.

Materials 463 (2015) 157-61

[12] A Widdowson et al., Experience of handling beryllium, tritium and activated components from JET ITER like wall, Physica Scripta T167 (2016) 01405710

[13] J. Likonen et al., Deuterium trapping and release in JET ITER-like wall divertor tiles Physica ScriptaT167 (2016) 014074

[14] I. Balboa, S. Silburn, et al. Recent developments of invessel calibration of mid-IR cameras at JET, Review of Scientific Instruments, 87 (2016) 11D419

[15] K. Heinola et al., Deuterium irradiation-induced defect concentrations in tungsten, Physica Scripta 2007(T128)91

[16] R. Behrisch et al. Quantitative analysis of deuterium in aC:D layers, a Round Robin experiment, Journal of Nuclear Materials 281 (2000) 42-56

[17] M. Reinelt et al. Retention mechanisms and binding states of deuterium implanted into beryllium, New Journal of Physics, 11 (2009) 043023

[18] M. Oberkofler et al. Towards a detailed understanding of the mechanisms of hydrogen retention in beryllium, Physica Scripta 2009 (T138) 014036

[19] C. Hurley et al.Numerical modeling of thermal desorption mass spectroscopy (TDS) for the study of hydrogen diffusion and trapping interactions in metals. International Journal of Hydrogen Energy, 40 (2015) 3402-3414

[20] D. Shiner, J.M. Gilligan, B.M. Cook, W. Lichten, Phys. Rev. A 47, 4042 (1993) or National Institute of Standards and Technology (NIST) Chemistry Webbook, NIST Standard Reference Database Number 69, US, http://webbook.nist.gov/chemistr

[21] K. Heinola et al., Long-term fuel retention in JET ITERlike wall, Physica Scripta T167 (2016) 014075

[22] M.J. Baldwin and R.P. Doerner, Nuclear Fusion 54 (2014) 083032

[23] M. Reineltand, Ch. Linsmeier, Physica Scripta T128 (2007) 111-114

[24] M. Mayer, Journal of Nuclear Materials240 (1997)164267

[25] A.A. Pisarev et al., Journal of Nuclear Materials 258-263 (1998) 1138-1142

[26] EUROFusion report: Activities carried out by IST for WPJET2 in 2015, E.Alves, N.Catarino, N.Barradas, V.Corregidor, 2016 